\title{
The role of ignimbrites and clays in the lithium distribution in a hyperarid environment: A geochemical and Li- isotopic approach in the Salar de \\ Atacama
}

\author{
FERNANDA ALVAREZ-AMADO ${ }^{1,2}$, MAURICIO \\ ROSALES $^{1}$, LINDA GODFREY ${ }^{3}$, ALONSO HIDALGO ${ }^{1}$, \\ DIEGO VOLOSKY ${ }^{1}$ AND CAMILA POBLETE-GONZÁLEZ ${ }^{1}$ \\ ${ }^{1}$ Universidad de Concepción \\ ${ }^{2}$ FCFM, Universidad de Chile \\ ${ }^{3}$ Rutgers University \\ Presenting Author: fernandaalvarez@udec.cl
}

Neogene and Quaternary ignimbrites of the Cordillera Occidental have been considered as the main source of $\mathrm{Li}$ in the Salar de Atacama. The contents of Li in Miocene, Pliocene and Pleistocene ignimbrites were analyzed in this research. A moderate enrichment (between 20 and $80 \mathrm{ppm}$ ) is recorded in these units, contrasting with the world-renowned accumulation in the salt flat. Ignimbrites of great thickness, proximal to the emission center or associated with the collapse of calderas, present low values of $\delta^{7} \mathrm{Li}$ (between $-1.5 \%$ and $+2.3 \%$ ). These values differ from the higher values measured in highly-vitreous and shards-abundant distal sequences, which display ratios varying between $+6.3 \%$ and $+12.8 \%$. The southern rocks of the salt flat would be key as a main source of the Li concentrated in the salt flat, considering the petrography and depositional features of them. Comparing the average Li content in rocks (37 $\mathrm{ppm})$ with respect to fine sediments (292 ppm) in the marginal zone of the Salar de Atacama, an enrichment close to an order of magnitude is observed. This enrichment would evidence the existence of significant concentration processes in the fine fraction of the salt flat related to the precipitation of secondary minerals. A predominance of clays like smectite and illite is identified by XRD, as well as gypsum in the marginal zone, whereas phases rich in $\mathrm{OH}$ are recognized from satellite images south of the salt flat. The large area of the Salar de Atacama favors an heterogenous distribution of elements that influence the $\mathrm{Li}$ concentration. In this sense, a higher content of $\mathrm{MgO}$ and $\mathrm{Na}_{2} \mathrm{O}$ is related to an increase of $\mathrm{Li}$ in sediments. Besides, a strong correlation between $\mathrm{As}, \mathrm{B}$ and $\mathrm{Li}$ is registered in sediments along the marginal zone, specially north of the saline nucleus. On the other hand, the Peine Block is an atypical zone, presenting anomalous $\delta^{7} \mathrm{Li}$ values regarding the rest of the salt flat. Hence, positive values in both sediments $(+4.36 \%)$ and suspended load $(+3.1 \%$ to $+7.2 \%$ ) were obtained in this zone. 